\title{
Ecoeficiência da produção agropecuária na Amazônia brasileira: fatores determinantes e dependência espacial
}

\section{Eco-efficiency of agricultural production in the Brazilian Amazon: determinant factors and spatial dependence}

João Vitor Borges da Silva1 (D), Carlos Rosano-Peña² (D), Michelle Márcia Viana Martins ${ }^{3}$ (D), Rafael Castro Tavares ${ }^{4}$ (D), Pedro Henrique Borges da Silva ${ }^{5}$ (D)

\author{
1Programa de Pós-graduação em Economia, Escola de Gestão e Negócios, Universidade Católica de Brasília (UCB), Brasília (DF), \\ Brasil. E-mail: borges.joaovitor@gmail.com \\ ²Programa de Pós-graduação em Administração, Faculdade de Administração, Contabilidade e Economia, Universidade de Brasília \\ (UnB), Brasília (DF), Brasil. E-mail: gmcrosano@gmail.com \\ ${ }^{3}$ Programa de Pós-graduação em Economia Aplicada, Escola Superior de Agricultura "Luiz de Queiroz", Universidade de São Paulo \\ (USP), São Paulo (SP), Brasil. E-mail: michellemartins@usp.br \\ 4Programa de Pós-graduação em Agronegócios, Faculdade de Agronomia e Medicina Veterinária, Universidade de Brasília (UnB), \\ Brasília (DF), Brasil. E-mail: rafaelcastro.adm@gmail.com \\ 5Programa de Pós-graduação em Economia, Faculdade de Administração, Contabilidade e Economia, Universidade de Brasília \\ (UnB), Brasília (DF), Brasil. E-mail: pedro.borges.96@gmail.com
}

Como citar: Silva, J. V. B., Rosano-Peña, C., Martins, M. M. V., Tavares, R. C., \& Silva, P. H. (2022). Ecoeficiência da produção agropecuária na Amazônia brasileira: fatores determinantes e dependência espacial. Revista de Economia e Sociologia Rural, 60(spe), e250907. https://doi.org/10.1590/1806-9479.2021.250907

\begin{abstract}
Resumo: A produção agropecuária na região amazônica avançou de forma exponencial, no entanto esse crescimento econômico resultou em significativos impactos ambientais nos ecossistemas desse bioma, como aumento do desflorestamento e da degradação da biodiversidade da floresta amazônica. Com esse enfoque, o presente artigo objetivou estimar a ecoeficiência da produção agropecuária dos municípios do bioma Amazônia, tendo como ênfase a discussão dos fatores determinantes e os desdobramentos espaciais desse indicador de sustentabilidade. Para isso, utilizou-se da metodologia DEA com duplo bootstrap e regressão truncada (DEA-BTR) e o índice espacial de Moran. A partir dos resultados, observou-se que a ecoeficiência média foi de 0,5490, indicando que os municípios amazônicos poderiam reduzir o consumo dos insumos e a pressão na biodiversidade em 45,01\%, em conjunto com a manutenção das receitas agropecuárias e da área preservada. Por outro lado, entre os fatores determinantes da sustentabilidade da agropecuária amazônica, a escolaridade do produtor e a assistência técnica estiveram positivamente associadas aos índices de ecoeficiência estimados, sendo essas as variáveis exógenas mais consistentes do modelo. Ademais, o índice global de Moran foi positivo e significativo estatisticamente, o que demonstrou a presença de autocorrelação da ecoeficiência agropecuária na Amazônia.
\end{abstract}

Palavras-chave: Amazônia, agropecuária, sustentabilidade, DEA-BTR.

\begin{abstract}
The agricultural production in the Amazon region has advanced exponentially. However, this economic growth has resulted in significant environmental impacts on the ecosystems of this biome, such as increased deforestation and degradation of biodiversity in the Amazon rainforest. Therefore, this article aimed to estimate the eco-efficiency of agricultural production in the municipalities of the Amazon biome, focusing on the determining factors and the spatial unfolding of this sustainability indicator. For that, we used the DEA methodology with double bootstrap and truncated regression (DEA-BTR) and the Moran Spatial Index. From the results, it was observed that the average eco-efficiency was 0.5490, indicating that the Amazonian municipalities could reduce the consumption of inputs and the pressure on biodiversity by $45.01 \%$ together with the maintenance of agricultural income and the preserved area. On the other hand, among the determining factors of sustainability of Amazonian agriculture, the level of education of the producer and technical assistance, being the most consistent exogenous variables of the models considered, were positively associated with the estimated eco-efficiency indexes. Furthermore, the Moran global index was positive and statistically significant, which demonstrated the presence of autocorrelation of agricultural eco-efficiency in the Amazon.
\end{abstract}

Keywords: Amazon, agriculture, sustainability, DEA-BTR 


\section{Introdução}

No último século, os sistemas agrícolas assumiram feições industriais. Se, antes, eram definidos por economias familiares caracterizadas pela autossuficiência, agora a produção alimentar se transforma a partir da incorporação da indústria pelo campo. O agronegócio, então, é marcado pelo processo de agroindustrialização, aumento de produtividade, alongamento das cadeias produtivas e concentração de recursos financeiros em atividades anteriores e posteriores à produção agrícola em si.

A agropecuária é fundamental para o desempenho econômico do Brasil, pois é um setor dinâmico com contribuições significativas para o produto interno bruto (PIB) e as exportações nacionais. Se a produção agrária representou, em 2019, 4,8\% do PIB, o agronegócio como um todo foi responsável por 21,2\% desse total no período (Medina, 2019).

A região da Amazônia, que, a princípio, seria um local menos propício ao cultivo agrícola e à pecuária, atualmente desempenha papel importante na produção alimentar nacional. Em termos de área de lavouras, tanto permanentes como temporárias, os municípios do bioma amazônico representam praticamente $16 \%$ da área total plantada, ao passo que a produção agropecuária, expressa em receita de vendas, representa 15\% dos rendimentos econômicos da produção agropecuária brasileira. De fato, o aumento da produção nas últimas décadas se expandiu também ao norte do país, tornando estados como Mato Grosso, Rondônia e Pará relevantes no contexto do agronegócio (Instituto Brasileiro de Geografia e Estatística, 2017).

Por outro lado, esse enfoque produtivista negligenciou a agenda ambiental em detrimento dos resultados econômicos, pois não apenas desconsiderou a interdependência entre ambos, como também o potencial de redução da capacidade de produção dos sistemas agrícolas a partir da degradação contínua do meio ambiente. Nas municipalidades inseridas na Amazônia brasileira, a expansão de sistemas agroprodutivos não sustentáveis, fundamentados na monocultura da soja e na pecuária intensiva, tem provocado aumento significativo da área de floresta desmatada. Em termos de desmatamento, após anos de tendência de queda nos incrementos anuais do impacto ambiental, esse indicador tem se deteriorado, com aumentos recentes que culminaram em 10,1 mil hectares desmatados (Instituto Nacional de Pesquisas Espaciais, 2020). Em relação a esse fato, o Brasil é colocado na berlinda internacional, tornandose alvo de pressões constantes para a elaboração de políticas que mitiguem os efeitos na referida localidade.

A produção agropecuária na região amazônica decorre de problemas estruturais, principalmente, vinculados à degradação ambiental oriunda do processo produtivo e à manutenção dos recursos naturais dos ecossistemas. Por isso, estudos de ecoeficiência, que contrapõem análises tradicionais de eficiência econômica, têm angariado relevância na literatura. Tanto por meio de metodologias não paramétricas como paramétricas, a incorporação de externalidades negativas no modelo teórico-metodológico das análises tradicionais possibilita estimar fronteiras de ecoeficiência que consideram eficiência ambiental em sua constituição (Berre et al., 2017).

Adicionalmente, essa discussão pode ensejar duas abordagens ainda emergentes na literatura do tema, especialmente nacional: (i) um estudo dos fatores exógenos, não controláveis pelo produtor, que condicionam o desempenho sustentável na região amazônica; e (ii) uma análise da dependência espacial dos indicadores de ecoeficiência estimados. Com efeito, a incorporação de um segundo estágio nas problemáticas tradicionais de eficiência econômico-ecológica é relevante porque permite subsidiar, de forma mais acurada, a elaboração de políticas públicas orientadas à produção agrícola e pecuária. 
Isto posto, surgem três questões de pesquisa a serem respondidas: é possível reduzir os impactos ambientais oriundos e o consumo dos insumos ao mesmo tempo que se mantém o nível de produção da agropecuária amazônica? Quais são os fatores exógenos determinantes da sustentabilidade da agropecuária dos municípios do bioma Amazônia? A ecoeficiência da região apresenta dependência espacial, isto é, varia de acordo com semelhanças geográficas?

Considerando as perguntas elencadas, o objetivo deste estudo é estimar a ecoeficiência da produção agropecuária dos municípios da Amazônia, tendo como ênfase a discussão dos fatores determinantes e os desdobramentos espaciais desse indicador de sustentabilidade. Abranger os aspectos espaciais na análise é importante para o delineamento de políticas pontuais para determinadas regiões, e essa é uma das contribuições do estudo em relação àqueles que abordam eficiência nas propriedades rurais. Outra contribuição reside em utilizar uma análise envoltória de dados em dois estágios, a partir do algoritmo de duplo bootstrap e regressão truncada (DEA-BTR), conforme sugestão de Simar \& Wilson (2007). Essa proposta contrapõe o modelo clássico DEA com retornos variáveis de escala, uma vez que este tende a gerar escores viesados e superestimados em relação à eficiência factual.

A combinação de algoritmos de bootstrap com a regressão Tobit no arcabouço da DEA resulta em um método semiparamétrico, uma técnica considerada robusta para a determinação dos fatores que podem interferir na ecoeficiência da agropecuária da região da Amazônia e para a construção de intervalos de confiança dos escores estimados. Essa proposta traz uma contribuição metodológica inovadora ao estado da arte, pois são escassos os artigos que abordam a eficiência da agricultura nacional de uma perspectiva da sustentabilidade com o referido procedimento. Ademais, a análise espacial também é um elemento atual, pois é relativamente pouco explorada na literatura a relação entre espaço geográfico e nível de ecoeficiência da agricultura e pecuária no Brasil.

Esse tema é relevante e requer discussões, sobretudo no pleito da expansão comercial brasileira, em que a preocupação mundial, a respeito da exploração sustentável da conservação da região amazônica, pode elevar o mérito do Brasil nos debates mundiais sobre o agronegócio sustentável. Os resultados encontrados serão discutidos em termos de sugestões de políticas no desenvolvimento econômico e ambiental no bioma.

\section{Fundamentação Teórica}

O conceito de ecoeficiência é a introdução de uma perspectiva de desenvolvimento sustentável na interface da eficiência ecológica nas análises tradicionais de eficiência econômica e produtividade. Isto posto, a concepção de sustentabilidade é central na fundamentação teórica das análises de ecoeficiência, pois é a gênese da incorporação dos impactos ambientais em um arcabouço microeconômico da teoria da produção.

De tal modo, retomando o conceito de sustentabilidade, em sua definição clássica, refere-se ao ato de propiciar um desenvolvimento econômico que atenda às necessidades da geração presente sem comprometer a capacidade das gerações futuras de atender a seus próprios condicionamentos (Brundtland, 1987). Desenvolvimento sustentável, de acordo o relatório da Organização das Nações Unidas (ONU), seria fundado em três pilares essenciais: um sistema econômico capaz de gerar excedentes em uma base autossuficiente e sustentada; um sistema social que fornece soluções para tensões e desigualdades sociais; e um sistema de produção que preserva a base ecológica dos ecossistemas.

Contudo, essa definição clássica não encerra as discussões a respeito de sua aplicabilidade em áreas específicas. Em uma ótica teórico-econômica, sustentabilidade é o estado em que a 
utilidade (ou consumo) de uma sociedade é não declinante ao longo do tempo (Perman et al., 2003). Em outras palavras, para que seja sustentável, o desenvolvimento deve manter o tempo todo a capacidade de provisão de utilidade per capita não declinante, de forma que as gerações futuras usufruam dela ou do maior nível de bem-estar das gerações pregressas.

Nesse sentido, a concepção de eficiência ecológica é uma incorporação microeconômica da formulação teórica de sustentabilidade, já que preserva a importância de minimizar os impactos ambientais oriundos da atividade econômica, a fim de que esta não conduza a base ecológica dos ecossistemas ao esgotamento. Formalmente, tendo esse conceito integrado ao arcabouço de eficiência e produtividade, ecoeficiência é a razão do valor econômico gerado por um índice agregado de pressões ambientais, que são as externalidades ambientais negativas adjacentes à produção (Kuosmanen \& Kortelainen, 2005). Neste artigo, considera-se um índice líquido de pressões ambientais, haja vista que há a incorporação de uma externalidade positiva que deve ser absorvida nessa formulação clássica. Com efeito, a ecoeficiência permite mensurar a sustentabilidade em uma dimensão relativa, quantificando o potencial de redução de impactos ambientais e incrementos de produção por meio de inovação e disseminação das melhores práticas identificadas em uma análise.

Essa abordagem, no contexto da agricultura e da pecuária, tem crescido em relevância nos últimos anos, e, de uma perspectiva relativa, há, atualmente, um volume similar de pesquisas de eficiência econômica e ecoeficiência (Silva \& Thomé, 2021), entre as quais a parte majoritária tem estimado os fatores determinantes do desempenho econômico-ecológico da agricultura de produtores de determinada região, seja com análise envoltória de dados (Data Envelopment Analysis - DEA) ou análise de fronteiras estocásticas (Stochastic Frontier Analysis - SFA). Rosano Peña et al. (2018), utilizando a SFA com funções de distâncias hiperbólicas, estimaram a ecoeficiência da agricultura na Amazônia. Os principais resultados indicaram que o custo de oportunidade da preservação de áreas verdes na região foi entre US\$89,39 e US\$170,37 ha/ano, sendo possível aumentar os produtos desejáveis em 19,5\% e, simultaneamente, reduzir a área degradada e os insumos empregados na produção em 16,36\%.

Por outro lado, utilizando a DEA em dois estágios, com duplo bootstrap e regressão truncada, Bonfiglio et al. (2017) analisaram a ecoeficiência de produtores rurais da região de Marcas, na Itália. Os resultados demonstraram que a maior parte dos estabelecimentos apresentou eficiência econômica e ambiental modesta, especialmente por conta de níveis indesejados de utilização de fertilizantes e pesticidas. O segundo estágio, de regressão truncada, indicou que os estabelecimentos mais ecoeficientes são aqueles que são dirigidos por produtores jovens e que participam de programas agroecológicos.

A partir de metodologia similar, com a diferença da utilização de apenas um procedimento de bootstrap, Godoy-Durán et al. (2017) avaliaram a ecoeficiência de pequenos produtores de horticultura no sudeste da Espanha. Pela discussão apresentada, a maior parte do nível de ecoineficiência se devia, principalmente, por conta de desperdício de recursos, ao passo que o desperdício de água e o balanço de nitrogênio não foram acentuados. Ademais, especialização, adoção de certificados de qualidade e pertencimento a cooperativas foram fatores determinantes da ecoeficiência agrícola na região.

Com isso, pode-se afirmar que pesquisas que utilizam a DEA em dois estágios para estimar tanto os índices de ecoeficiência agropecuária como seus fatores condicionantes têm angariado popularidade na literatura. Entretanto, ainda são mais escassas nessa área as abordagens de ecoeficiência que considerem o efeito do espaço como um possível determinante correlacionado desse desempenho econômico e ambiental. Rosano-Peña et al. (2020), nesse sentido, analisaram os índices de ecoeficiência da agricultura dos municípios de São Paulo por meio da DEA com 
funções de distâncias direcionais e realizaram uma análise exploratória de dados espaciais (Exploratory Spatial Data Analysis - ESDA) para verificar a hipótese de autocorrelação e heterogeneidade espacial da ecoeficiência na região.

Seus resultados indicaram que, em média, as municipalidades poderiam reduzir insumos e áreas degradadas em 59\%, ao mesmo tempo que incrementariam a produção nessa mesma proporção. A análise espacial, por fim, demonstrou a existência de heterogeneidade e autocorrelação espacial entre os municípios e a formação de grandes clusters, fato que reforçou a importância de considerar a dependência espacial da produção agrícola em análises similares. Esse apontamento reforça a possibilidade de aplicar políticas pontuais, otimizando os recursos no atendimento de determinados objetivos.

Contribuindo com o estado da arte, apresenta-se uma metodologia robusta em estimar a ecoeficiência da agropecuária para os municípios da região amazônica, fornecendo subsídios empíricos para racionalizar o uso dos insumos produtivos, buscando alcançar eficiência, ao mesmo tempo que promove a sustentabilidade e a conservação dos ecossistemas na Amazônia.

\section{Metodologia}

A DEA é um método não paramétrico desenvolvido por Charnes et al. (1978), a partir do trabalho seminal de Farrell (1957), para mensurar eficiência relativa de unidades tomadoras de decisões. Baseada em problemas de programação linear (PPL), a DEA é uma técnica multifatorial de mensuração de eficiência que estima uma fronteira empírica de melhores práticas a partir de um conjunto de possibilidades de produção. Nesse processo de programação matemática, o método considera que as unidades tomadoras de decisão (Decision Making Units - DMUs) se enquadram em um processo de produção clássico, com transformaação de múltiplos insumos em múltiplos produtos (Charnes et al., 1978).

A principal vantagem da metodologia DEA é que, em contraposição aos métodos paramétricos, não impõe a necessidade de uma forma funcional que represente os dados e tampouco requer hipóteses sobre a distribuição dos resíduos, o que garante maior flexibilidade na abordagem de múltiplas entradas e saídas (Toma et al., 2017). Em outras palavras, a fronteira de eficiência é estimada empiricamente, isto é, a partir das observações registradas nos dados, de forma que a DEA define a eficiência de cada unidade segundo os pesos alocados pelo próprio PPL. Com isso, para todos os casos, define-se o vetor ótimo de minimização dos insumos ou maximização dos produtos que permitiria reduzir a ineficiência de determinada unidade e classificá-la entre as melhores práticas, ou como benchmark para aquela amostra (Kuosmanen \& Kortelainen, 2005).

Desta forma, pode-se afirmar que os modelos clássicos DEA se dividem entre aquele que assume retornos constantes de escala (Constant Return to Scale, DEA-CRS) e o que assume retornos variáveis de escala (Variable Returns to Scale, DEA-VRS), em que cada versão pode ser orientada ao insumo ou ao produto. Se orientado ao produto, o modelo calcula as unidades que maximizam sua produção, mantendo constantes os insumos; se orientado aos insumos, as unidades eficientes são aquelas que minimizam os insumos, mantendo constantes os produtos.

Além dos modelos tradicionais, outros foram empregados na literatura com o objetivo de superar limitações originárias da natureza dessa técnica. Um grupo de técnicas mais robustas que visa superar a limitação determinística desse método é a DEA dois estágios. Assim, este artigo descreverá e utilizará, em um primeiro momento, o modelo clássico com retornos variáveis, DEA-BCC (a sigla BCC faz alusão aos autores Banker et al., 1984) e, posteriormente, empregará sua variante com dois estágios: a DEA com duplo bootstrap e regressão truncada. 


\subsection{Modelo de um estágio: DEA-BCC}

O modelo clássico utilizado aqui é aquele desenvolvido por Banker et al. (1984), a análise envoltória de dados com retornos variáveis de escala (DEA-VRS), também chamada de DEABCC, que tem como premissa a consideração de retornos variáveis de escala no processo produtivo. Se, no modelo de retornos constantes de escala, pressupunha-se proporcionalidade, na DEA com retornos variáveis há a substituição pela hipótese de convexidade entre insumos e produtos, que faz com que as unidades produtivas sejam comparadas apenas a outras unidades de características produtivas similares.

A Equação 1 é a versão "envelopada" e matricial do problema matemático para mensurar a eficiência orientada ao produto da unidade $i$. Aqui, $n$ é um vetor exclusivamente composto por valores unitários. Na restrição $\bar{n} \bar{\lambda}=1$, garante-se que a soma dos 's seja igual a 1 , o que impede que uma DMU seja comparada com outras muito diferentes dela. Assim, se uma unidade é eficiente, o escore $\eta_{i}$ será igual a 1; caso esteja abaixo de 1, a unidade é ineficiente. Um escore de 0,8, por exemplo, no modelo orientado aos insumos, indica que a unidade poderia reduzir seu consumo de recursos em $20 \%$, mantendo constante seu produto. Em um modelo orientado aos produtos, esse mesmo escore indica um aumento factível de $20 \%$ dos outputs, fixado o consumo dos recursos.

Com essas combinações lineares condicionadas, as unidades com vetores de insumo ou produto consideravelmente maiores ou menores não são integradas no conjunto referência da DMU investigada. Nesse problema, o inverso do valor $h_{0}$ maximizado indica a expansão factível de todos os produtos dada uma quantidade fixa de insumos empregados. Portanto, trata-se de um problema de programação linear (PPL) orientado aos produtos.

$\max \theta_{i}$

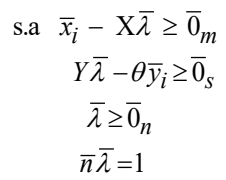

Na Equação $1, \theta_{i}$ é o escore de eficiência da DMU ${ }_{i}$ e $\bar{x}_{i}$ é o vetor $(m \times 1)$ de insumos utilizados por essa unidade. Pelas restrições, $y$ é o vetor $(s \times 1)$ de produtos gerados, $\bar{\lambda}$ é o vetor $(n \times 1)$ de pesos para combinações lineares das melhores práticas que formam a fronteira eficiente, $x$ é uma matriz $(m \times n)$ formada pelos vetores de insumos e ${ }_{Y}$ é uma matriz $(s \times n)$ de produtos da amostra.

Neste trabalho, como a intenção reside em avaliar tanto a expansão ótima da produção, mantendo constante os insumos, quanto a contração ótima dos insumos, mantendo constante a produção, os problemas lineares considerados são orientados aos inputse aos outputs. A versão orientada aos insumos do PPL anterior é análoga, em que este passa a ser um problema de minimização com restrições similares de normalização.

Logo, o modelo tradicional de DEA com retornos variáveis de escala será utilizado neste trabalho como base para o segundo estágio do problema, em que são realizados dois procedimentos de bootstrap e a regressão truncada das variáveis exógenas. Além disso, o primeiro estágio será empregado também para efeitos comparativos entre os escores sem o procedimento e com o procedimento de reamostragem.

\subsection{Modelo de dois estágios: DEA-BTR}

O modelo de DEA com Bootstrap Truncated Regression (BTR) deste artigo refere-se à técnica proposta por Simar \& Wilson (2007), que consiste em uma regressão truncada no segundo 
estágio com duplo bootstrap, que possibilita testar a significância das variáveis independentes e calcular os intervalos de confiança para os escores de eficiência. A aplicação do BTR no segundo estágio, em vez de outras alternativas existentes na literatura, justifica-se, entre outros aspectos, principalmente pelo problema de correlação serial que as estimativas DEA apresentam. Em outras palavras, alterações nas observações situadas na fronteira estimada quase sempre causarão mudanças nas eficiências estimadas, o que viola premissas básicas da regressão (Bonfiglio et al., 2017).

Assim, de acordo com Simar \& Wilson (2007), a regressão truncada pode ser descrita segundo a Equação 2:

$$
\begin{gathered}
\tilde{\theta}_{i} \approx \beta Z_{i}+\varepsilon_{i} \\
i=1, \ldots, n
\end{gathered}
$$

de modo que $\tilde{\theta}_{i}=\hat{\theta}_{i}-\operatorname{Bias}\left(\hat{\theta}_{i}\right)$, em que $\tilde{\theta}_{i}$ representa os escores corrigidos de viés e o termo $\operatorname{Bias}\left(\hat{\theta}_{i}\right)$ representa o viés e pode ser estimado pelo procedimento de bootstrap. Com efeito, a DEA-BTR produz resultados mais consistes que outras variantes de dois estágios, como a regressão Tobit, tendo obtido maior frequência de utilização em pesquisas de eficiência agrícola nos últimos anos (Zulfiqar, Datta, \& Thapa, 2017). De forma mais precisa, o procedimento utilizado neste trabalho é o algoritmo 2 de Simar \& Wilson (2007), caracterizado por dois loops, a saber, um para estimar os índices corrigidos e outro para construir intervalos de confiança. Os passos do algoritmo são descritos a seguir:

1. Estimar a ecoeficiência dos municípios por meio do modelo clássico DEA-VRS.

2. Por meio do método de máxima verossimilhança, obter as estimativas de $\hat{\beta}$ e $\hat{\sigma}_{e}$ de seus parâmetros populacionais da regressão truncada.

3. Para cada município, repetir os quatro passos seguintes $L_{1}$ vezes para produzir o conjunto de estimativas $B_{i}=\left\{\hat{\theta}_{i b}^{*}\right\}_{b=1}^{L_{1}}$ :

a. Extrair os resíduos $\varepsilon_{i}$ da distribuição $N\left(0, \hat{\sigma}_{e}^{2}\right)$.

b. Estimar $\theta_{i}^{*}=Z_{i} \hat{\beta}+\varepsilon_{i}$.

c. Produzir uma pseudobase de dados $\left(x_{i}^{*}, y_{i}^{*}\right)$, em que $x_{i}^{*}=\hat{\theta}_{i} / \theta_{i}^{*}$ e $y_{i}^{*}=y_{i}$ se o modelo for orientado aos insumos, e o inverso, com os produtos transformados se o modelo tiver orientação aos produtos.

d. Estimar a pseudoecoeficiência $\hat{\theta}_{i}^{*}$ com base na pseudobase gerada, em que os vetores de insumos e produtos são substituídos por $X^{*}$ e $Y^{*}$.

4. Para cada município, estimar o índice $\tilde{\theta}_{i}$ definido na Equação 3 utilizando as estimativas de bootstrap obtidos no passo anterior e as estimativas originais: $\tilde{\theta}_{i}=\hat{\theta}_{i}-\operatorname{Bias}\left(\hat{\theta}_{i}\right)$. O viés é calculado por $\widehat{\operatorname{Bias}}\left(\hat{\theta}_{i}\right)=\overline{\hat{\theta}_{i b}^{*}}-\hat{\theta}_{i}$, em que $\overline{\hat{\theta}_{i b}^{*}}=\frac{1}{L_{1}} \sum_{b=1}^{L_{1}} \hat{\theta}_{i b}^{*}$.

5. Utilizar o método de máxima verossimilhança para estimar a regressão truncada $\tilde{\theta}_{i} \operatorname{com} Z_{i}$ para gerar os parâmetros estimados $\hat{\hat{\beta}}$ e $\hat{\sigma}_{e}$.

6. Repetir os próximos passos $L_{2}$ vezes para produzir um conjunto de estimativas de bootstrap $\Gamma=\left\{\left(\hat{\beta}^{*}, \hat{\sigma}_{e}^{*}\right)_{b}\right\}_{b=1}^{L_{2}}$

a. Para cada município, extrair os resíduos $\varepsilon_{i}$ da distribuiç̧ão $N\left(0, \hat{\hat{\sigma}}_{e}^{2}\right)$.

b. Para cada município, computar $\theta_{i}^{* *}=Z_{i} \hat{\hat{\beta}}+\varepsilon_{i}$. 
c. Utilizar o método de máxima verossimilhança para estimar a regressão truncada de $\theta_{i}^{* *}$ para gerar as estimativas $\hat{\hat{\beta}}$ e $\hat{\sigma}_{e}^{*}$.

7. Utilizar as estimativas г e as estimativas $\hat{\hat{\beta}}$ e $\hat{\hat{\sigma}}_{e}$ para construir intervalos de confiança para cada $\beta$ e. .

Ressalta-se que os dois procedimentos de bootstrap, $L_{1}$ e $L_{2}$, foram obtidos a partir de 100 e 2.000 iterações, respectivamente, que são os números de iterações recomendadas por Simar \& Wilson (2007) no algoritmo 2. Ademais, para este artigo, a DEA-BTR será utilizada em orientação aos insumos e aos produtos, de forma a verificar o efeito das variáveis exógenas, considerando ambas as alternativas de projeção na fronteira.

\subsection{Dependência espacial: estatística I de Moran}

Para alcançar o objetivo de testar a hipótese de dependência espacial da ecoeficiência da agropecuária dos municípios do bioma Amazônia, utilizou-se nesta pesquisa da estatística I de Moran, que permite estimar a correlação espacial de fenômenos. Em síntese, esta se baseia em uma medida de autocovariância, uma medida de variância dos dados e uma matriz de pesos espaciais. Algebricamente, essa técnica é representada pela Equação 3, em que $n$ é o número total de observações, $w_{i j}$ é o peso, em que a unidade indica que as observações $i$ e ${ }_{j}^{j}$ são vizinhas, e $y_{i}$ e $\bar{y}$ representam o valor da variável de interesse na localização $i$ e a média dessa variável, respectivamente (Moran, 1948).

$I=\frac{n}{\sum_{i}^{n} \sum_{j}^{n} w_{i j}} \times \frac{\sum_{i}^{n} \sum_{j}^{n} w_{i j}\left(y_{i}-\bar{y}\right)\left(y_{j}-\bar{y}\right)}{\sum_{i}^{n}\left(y_{i}-\bar{y}\right)^{2}}$

Assim, quando $I=1$, tem-se que o conjunto espacial apresenta extrema autocorrelação positiva, em que os municípios apresentam feições de similaridade para um atributo, ao passo que, quando $I=-1$, esse conjunto apresenta extrema autocorrelação negativa, que significa que os municípios apresentam feições de dissimilaridade. Ademais, esse indicador global, que representa toda a amostra em uma única estatística, pode ser decomposto em índices locais para cada unidade geográfica, a fim de possibilitar a análise de padrões espaciais locais. Com efeito, utilizou-se também do índice local de Moran para detectar a formação de clusters ou valores atípicos de ecoeficiência ao longo do território do bioma Amazônia (Anselin, 1995).

A combinação metodológica da DEA com a estatística I de Moran é um procedimento que tem sido observado recentemente. Rosano-Peña et al. (2020), por exemplo, atrelaram à análise dos índices de ecoeficiência da agricultura os efeitos espaciais. Ressalta-se, assim, que a análise espacial deste trabalho se restringe à mensuração da autocorrelação espacial e de agrupamentos locais de desempenho agropecuário, similar ao que foi realizado pelos autores para testar a hipótese de que o espaço está relacionado com a ecoeficiência do setor na região. Como em Rosano-Peña et al. (2020), a estimação de modelos econométricos espaciais foge do escopo deste trabalho.

\subsection{Descrição das variáveis}

Para analisar a ecoeficiência agropecuária dos 552 municípios do bioma Amazônia, extraíram-se informações de insumos e produtos do Censo Agropecuário 2017 (Instituto Brasileiro de Geografia e Estatística, 2017). A amostra do estudo é baseada em dados cross-section, de modo que as informações são restritas ao ano de 2017, último período disponível no Censo Agropecuário do 
IBGE. Entre os inputs, utilizou-se de: (i) $x_{1}$ - área utilizada com cultivo; (ii) $\chi_{2}$ - área utilizada com pastagens; (iii) $x_{3}$ - capital; (iv) $x_{4}$ - despesas com insumos; e (v) $x_{5}$ - mão de obra. Para os outputs, as variáveis eleitas foram: (i) $y_{1}$ - receita agrícola; e (ii) $y_{2}$ - receita da pecuária.

Duas medidas foram empregadas para caracterizar as externalidades ambientais, cada qual para expressar as externalidades negativas e positivas: (i) negativa, $y_{b}$ - impacto na biodiversidade. Por limitações do pacote estatístico utilizado para estimar a DEA em dois estágios, esta foi modelada como um insumo, de forma a ser minimizada nos cálculos dos PPL; e (ii) positiva, $y_{3}$ área preservada. Por ser um produto desejável, foi alocada com os produtos clássicos.

Finalmente, entre as variáveis exógenas, potencialmente associadas à ecoeficiência da agropecuária amazônica, escolheram-se sete elementos que viriam a interferir na dinâmica produtiva ambiental. A escolha dessas variáveis ocorreu com base em trabalhos que apresentavam um retrato consistente das variáveis que pudessem interferir na eficiência/ ineficiência das propriedades rurais no Brasil, quais sejam: os estudos de Khan \& Silva (1997), Clemente et al. (2015), Silva et al. (2017) e Brianez \& Sabbag (2021). As variáveis exógenas são: (i) $z_{1}$ - agricultura familiar: \% da mão de obra familiar em relação ao total; (ii) $z_{2}$ - associação à cooperativa: \% dos estabelecimentos associados a cooperativas; (iii) $z_{3}$ - assistência técnica: $\%$ dos estabelecimentos que receberam assistência técnica; (iv) $z_{4}$ - escolaridade: \% dos estabelecimentos cujo produtor possui pelo menos ensino médio; $(v) z_{5}$ - terras próprias: $\%$ dos estabelecimentos cujo produtor é proprietário; (vi) $z_{6}$ - sexo: \% dos estabelecimentos cujo produtor principal é mulher; (vii) $z_{7}$ - crédito: \% dos estabelecimentos que obtiveram financiamento. A Tabela 1 apresenta a descrição detalhada das variáveis de inputs e outputs utilizadas, já que elas são centrais ao modelo.

Tabela 1. Descrição dos inputs e outputs utilizados no modelo.

\begin{tabular}{|c|c|}
\hline Variável & Descrição \\
\hline \multicolumn{2}{|l|}{ Inputs } \\
\hline$x_{1}$ - Área utilizada com & Área dos estabelecimentos destinada à produção agrícola (lavouras \\
\hline lavouras & temporárias e permanentes), em hectares. \\
\hline$x_{2}$ - Área utilizada com & Área dos estabelecimentos destinada a pastagens naturais e pastagens em \\
\hline pastagens & boas condições (não degradadas), em hectares. \\
\hline$x_{3}$ - Capital & $\begin{array}{l}\text { Proxy: número de tratores, implementos e máquinas existentes nos } \\
\text { estabelecimentos agropecuários em } 2017 .\end{array}$ \\
\hline$x_{4}-$ Despesas com & Despesas com insumos para produção vegetal e animal (adubos, corretivos, \\
\hline insumos & sementes, compra de animais, agrotóxicos etc.), em mil reais ( $R \$)$. \\
\hline$x_{5}$ - Mão de obra & $\begin{array}{l}\text { Pessoal ocupado nos estabelecimentos agropecuários em } 2017 \text { (assalariado e } \\
\text { familiar). }\end{array}$ \\
\hline \multicolumn{2}{|l|}{ Outputs } \\
\hline$y_{1}$ - Receita agrícola & Receita obtida com venda de produtos vegetais, em mil reais ( $\mathrm{R} \$$ ). \\
\hline $\begin{array}{l}y_{2} \text { - Receita pecuária } \\
\text { Externalidades }\end{array}$ & Receita obtida com venda de produtos de origem animal, em mil reais (R\$). \\
\hline$y_{3}$ - Área preservada & $\begin{array}{l}\text { Consiste na área de matas e florestas dos estabelecimentos destinada à } \\
\text { preservação permanente (APPs) ou reserva legal, em hectares. }\end{array}$ \\
\hline $\begin{array}{l}y_{b}-\text { Impacto na } \\
\text { biodiversidade }\end{array}$ & $\begin{array}{l}\text { Índice de impacto na biodiversidade, que é calculado segundo o índice de } \\
\text { Shannon (SHDI) }{ }^{1} \text {. }\end{array}$ \\
\hline
\end{tabular}

Fonte: elaborada pelos autores.

\footnotetext{
1 O índice de Shannon é uma proxymuito utilizada na literatura de ecoeficiência para estimar o impacto da agricultura na biodiversidade. Ele é calculado por $b_{1 i}=1 / e^{S H D I}$, em que $S H D I=-\sum_{c=1}^{C}\left(s_{c i} \cdot \ln s_{c i}\right)$ e $s_{c i}=A_{r e a} / a_{c i}$ Area $i$ (Beltrán-Esteve et al., 2012, p. 918). Resumidamente, esse índice considera o número de culturas de um estabelecimento e sua regularidade de distribuição. A pressão na biodiversidade pode assumir valores entre 0 e 1, em que o valor da unidade representa estabelecimentos que produzem apenas um tipo de cultura, e, conforme este decresce e tende a zero, significa um maior número de culturas e uma distribuição mais regular entre elas. Portanto, uma maior especialização produtiva produz efeitos mais negativos na fauna e flora circunvizinhas, capturadas por indicadores próximos a 1.
} 


\section{Resultados e Discussão}

Antes da operacionalização da análise de ecoeficiência proposta como objetivo principal, realizou-se um tratamento de outliers existentes na base de dados, haja vista que a fronteira de eficiência estimada da DEA é sensível a valores extremos (Huy \& Nguyen, 2019). A metodologia de data cloud, proposta por Bogetoft \& Otto (2011), foi a escolhida, pois é uma técnica robusta de identificação de valores atípicos. De forma resumida, observa-se o volume da matriz combinada de insumos e produtos, em que uma redução significativa desse volume, a partir da retirada de uma DMU, seria um indicativo de que essa unidade é um outlier. Outra técnica empreendida foi a de criação de faixas de cortes por meio da estimação da DEA com supereficiência (Bogetoft \& Otto, 2011)

Essa complementação foi necessária, pois o algoritmo da metodologia de data cloud exige muitos recursos computacionais. Com efeito, removeram-se 25 municípios do bioma amazônico, em que 9 apresentaram viabilidade de aumentar seus recursos em $500 \%$ e, ainda assim, permanecer na fronteira de ecoeficiência. De fato, trata-se de escores consideravelmente acima da capacidade de produção de outras regiões, em termos relativos.

Por fim, para melhor introduzir a análise e garantir uma compreensão holística e inicial da amostra de estudo como um todo, a Tabela 2 registra as estatísticas descritivas das variáveis de insumos, produtos e externalidade ambiental conforme indicadas na seção anterior.

Tabela 2. Estatísticas descritivas dos insumos e produtos.

\begin{tabular}{|c|c|c|c|c|c|}
\hline Variável & Média & Mediana & $\begin{array}{l}\text { Desvio- } \\
\text { padrão }\end{array}$ & Máximo & Mínimo \\
\hline $\begin{array}{l}x_{1}-\text { Área utilizada } \\
\text { com lavouras }\end{array}$ & 14.751 & 3.089 & 37.994 & 345.397 & 30 \\
\hline $\begin{array}{l}\boldsymbol{x}_{2} \text { - Área utilizada } \\
\text { com pastagens }\end{array}$ & 68.964 & 33.444 & 96.276 & 633.479 & 2 \\
\hline $\boldsymbol{x}_{3}$ - Capital & 239,76 & 107 & 371,71 & 2.562 & 0 \\
\hline $\begin{array}{l}\boldsymbol{x}_{4} \text { - Despesas com } \\
\text { insumos }\end{array}$ & 63.985 & 24.284 & 119.878 & 1.000 .792 & 259 \\
\hline $\boldsymbol{x}_{5}$ - Mão de obra & 4.418 & 3.296 & 4.263 & 48.246 & 304 \\
\hline$y_{1}$ - Receita agrícola & 47.316 & 6.144 & 144.191 & 13.964 .686 & 4 \\
\hline $\begin{array}{l}\boldsymbol{y}_{2} \text { - Receita } \\
\text { pecuária }\end{array}$ & 45.016 & 23.107 & 61.338 & 498.545 & 82 \\
\hline $\begin{array}{l}\boldsymbol{y}_{3}-\text { Área } \\
\text { preservada }\end{array}$ & 51.807 & 18.124 & 82.301 & 689.156 & 0 \\
\hline $\begin{array}{l}\boldsymbol{y}_{\boldsymbol{b}} \text { - Impacto na } \\
\text { biodiversidade }\end{array}$ & 0,59 & 0,61 & 0,26 & 0,99 & 0,07 \\
\hline
\end{tabular}

Fonte: elaborada pelos autores.

\subsection{Análise dos escores de ecoeficiência}

Para efeitos de análise da produção agropecuária, considera-se que os produtores rurais têm maior controle da alocação de insumos do que de seu nível de produção, pois este é mais sujeito à influência de fatores exógenos, como alterações climáticas e variáveis macroeconômicas. Com isso, o modelo DEA empregado para a análise dos índices de ecoeficiência foi calculado com orientação aos insumos. 
A ecoeficiência foi calculada tanto pelo modelo determinístico DEA-VRS como pela técnica de duplo bootstrap de Simar \& Wilson (2007), mais especificamente o procedimento L1 da técnica DEA-BTR. A Tabela 3 apresenta os resultados dos escores do modelo básico e dos escores corrigidos de viés, em um intervalo de confiança de 95\%. Desta forma, o escore determinístico médio de 0,6747 indica que os municípios amazônicos poderiam otimizar o consumo dos insumos e melhorar a pressão na biodiversidade em $32,53 \%$, preservando as receitas agropecuárias e a manutenção da área preservada. Por outro lado, a mediana próxima da média, de 0,6437, reforça a efetividade da remoção de outliers.

Tabela 3. Ecoeficiência média da agropecuária amazônica.

\begin{tabular}{ccc} 
Descrição & Determinístico $\hat{\theta}_{i}$ & Bootstrap $\tilde{\theta}_{i}$ \\
Média & 0,6747 & 0,5490 \\
Viés & - & 0,1256 \\
IC 95\% sup. & - & 0,6296 \\
IC 95\% inf. & - & 0,4764 \\
Mediana & 0,6437 & 0,5534 \\
Máximo & 1,0000 & 0,8837 \\
Mínimo & 0,2024 & 0,1552 \\
\hline
\end{tabular}

Fonte: elaborada pelos autores.

Contudo, esses índices são viesados, isto é, superestimam a ecoeficiência para as municipalidades em estudo. Em razão disso, os índices gerados pelo procedimento de bootstrap são mais robustos por terem esse problema minimizado. A ecoeficiência média para os escores corrigidos, portanto, foi de 0,5490 , valor que indica uma possibilidade de os municípios ecoineficientes reduzirem os recursos e o impacto na biodiversidade em 45,1\%, ao mesmo tempo que mantêm o nível de produção e a área de reserva legal e APPs. O viés estimado de 0,1256 é uma diferença significativa em termos de eficiência econômico-ecológica, o que justifica a relevância de considerar distúrbios aleatórios na estimação desses índices.

Adicionalmente, pelo modelo clássico com retornos variáveis de escala, 18\% dos municípios (totalizando 96) foram ecoeficientes, ao passo que, com a correção de viés pelo procedimento de reamostragem, nenhum município atingiu o nível ótimo estimado na fronteira original. Isso indica que mesmo aqueles considerados como melhores provedores das melhores práticas dentro do contexto não alocavam seus recursos eficientemente e não minimizavam o impacto na biodiversidade gerado pela especialização produtiva. Em outras palavras, por conta dos resíduos estimados na DEA-BTR, a ecoeficiência máxima nesse modelo foi de 0,8837.

Para melhor capturar a dimensão da diferença entre os escores determinísticos e os escores com bootstrap, podem-se utilizar o índice de impacto na biodiversidade e o nível de despesas para estimar as projeções médias na fronteira. No que tange à pressão na biodiversidade, a média desse dado para os municípios do bioma em análise foi de 0,5983. Já a despesa com insumos foi de, em média, $\mathrm{R} \$ 63.984 .920$ para esse mesmo contexto. Assim, a partir do índice determinístico de ecoeficiência estimado, um município representativo da Amazônia poderia reduzir seus gastos com insumos produtivos em quase $R \$ 21$ milhões, bem como o impacto na biodiversidade em 0,19 unidade do índice de Shannon.

Todavia, essa projeção é subestimada, haja vista que o escore corrigido indicou uma redução potencial de $R \$ 29$ milhões em despesas e em 0,09 unidade do impacto na diversidade ecológica, em uma diferença de aproximadamente $\mathrm{R} \$ 7$ milhões para os resultados médios viesados. Com efeito, essa análise corrobora a importância de se estimar a DEA com procedimento 
de bootstrap, pois, assim, é possível estimar indicadores de ecoeficiência mais precisos, que subsidiem políticas públicas com metas adequadas à realidade do produtor rural desse bioma.

\subsection{Fatores determinantes da ecoeficiência}

Nesse segundo estágio, realizou-se a regressão truncada à esquerda, cujos resultados são apresentados como fatores determinantes da ecoeficiência da produção agropecuária na Tabela 4. Diferentemente da análise dos escores, é relevante observar o impacto da escolha do modelo, isto é, se é orientado aos insumos ou aos produtos, na estimação dos coeficientes da regressão. Ademais, tendo em vista que este trabalho utiliza uma externalidade negativa e outra positiva, analisar as variáveis condicionantes da eficiência econômico-ecológica em termos da preservação de áreas é igualmente importante para subsidiar políticas públicas.

Tabela 4. Fatores determinantes da ecoeficiência agropecuária amazônica (orientação aos insumos).

\begin{tabular}{lccc}
\multicolumn{1}{c}{ Variável } & Coeficientes & IC inf. 2,5\% & IC sup. 97,5\% \\
\hline Intercepto & $2,950 * *$ & 1,6738 & 4,2343 \\
$z_{1}$ - Mão de obra familiar & $-0,2353$ & $-1,4429$ & 0,9476 \\
$z_{2}$ - Trabalho infantil & $-1,5714$ & $-4,7536$ & 1,7234 \\
$z_{3}$ - Assistência técnica & $-5,0058 * * *$ & $-6,9892$ & $-2,7039$ \\
$z_{4}$ - Escolaridade & $-5,4207 * * *$ & $-7,7622$ & $-2,8939$ \\
$z_{5}$ - Terras próprias & 0,4689 & $-0,3550$ & 1,2240 \\
$z_{6}$ - Sexo & $-1,5360$ & $-3,8362$ & 0,9665 \\
$z_{7}$ - Crédito & $3,1138 * * *$ & 0,9534 & 5,4037 \\
$\hat{\sigma}_{\boldsymbol{e}}$ & $1,1232 * * *$ & 0,9724 & 1,2718 \\
\hline
\end{tabular}

Fonte: elaborada pelos autores. Nota: *** significante a $1 \%$; ** significante a $5 \%$; * significante a $10 \%$.

Com efeito, para o modelo de ecoeficiência do uso de insumos e do impacto na biodiversidade, a Tabela 4 apresenta os coeficientes da regressão das variáveis explicativas nos índices estimados. O intervalo de confiança utilizado como base foi de $\alpha=0,05$, mas há o indicativo da significância estatística a $1 \%, 5 \%$ e $10 \%$. Ressalta-se também que o sinal negativo do coeficiente representa que a variável tem um efeito positivo na ecoeficiência, ao passo que um sinal positivo indica um efeito negativo, ou seja, as variáveis são inversamente relacionadas. Isso se explica pelo fato de que os índices do primeiro estágio são estimados pelo recíproco da eficiência de Farrell, cujo intervalo está entre 1 e infinito.

Assim, na DEA-BTR orientada aos insumos, o recebimento de assistência técnica e a escolaridade do produtor rural estão associados positivamente com o nível de ecoeficiência de um município. Com os valores dos coeficientes mais altos e sendo significativos estatisticamente, esses dados apontam para a importância de a esfera pública e as entidades do terceiro setor assistirem e orientarem os produtores da Amazônia na implementação das técnicas sustentáveis de produção, bem como o Estado garantir educação básica no meio rural. Na literatura recente de ecoeficiência, Guesmi et al. (2018) e Huy \& Nguyen (2019) discutem resultados similares para essas duas variáveis ao analisarem a eficiência técnica de produtores do Vietnã e do Egito, respectivamente. De fato, esse impacto positivo é amplamente verificável nos estudos do tema.

Por outro lado, outra variável significante estatisticamente é a porcentagem de estabelecimentos que obtiveram acesso ao crédito agrícola, mas a estimativa sugere relação negativa entre ela e o nível de ecoeficiência agropecuária desses municípios. Esse resultado é contrário à expectativa e a outros estudos da literatura recente, como em Chandio et al. (2019), pois espera-se que o acesso ao crédito seja um fator condicionante positivo desse desempenho. 
Contudo, Masuku et al. (2014) afirmam que o acesso ao crédito pode diminuir ou aumentar o desempenho produtivo de um estabelecimento, especialmente quando esse financiamento está relacionado à aquisição de insumos de alto valor, como maquinários.

Complementarmente, esse efeito poderia ser explicado pelo nível de aversão ao risco de produtores especializados, isto é, a incerteza de retornos financeiros poderia resultar em empréstimos de alto risco para os agentes financiadores. Esse cenário é oposto ao de outros produtores de menor especialização, pois estes pulverizam esse risco por causa da sua diversificação de produção (Kansiime et al., 2018). Adicionalmente, os coeficientes estimados para mão de obra familiar, trabalho infantil, terras próprias e sexo do produtor foram estatisticamente iguais a zero, de forma que não é possível concluir se existe uma relação de causalidade entre elas e o nível de ecoeficiência agropecuária

Pelo modelo de orientação aos produtos, a Tabela 5 contém os resultados dos coeficientes, a significância estatística destes e o intervalo de confiança a 5\%, em que se testa o efeito das variáveis explicativas na ecoeficiência agropecuária amazônica, com foco na maximização das receitas e nas áreas preservadas.

Tabela 5. Fatores determinantes da ecoeficiência agropecuária amazônica (orientação aos produtos).

\begin{tabular}{lccc}
\multicolumn{1}{c}{ Variável } & Coeficientes & IC inf. 2,5\% & IC sup. 97,5\% \\
Intercepto & $11,8360^{* *}$ & 1,2420 & 24,1561 \\
$z_{1}$ - Mão de obra familiar & $-5,8618$ & $-18,1888$ & 5,5244 \\
$z_{2}$ - Trabalho infantil & $-43,4379^{* * *}$ & $-84,1475$ & $-15,2362$ \\
$z_{3}$ - Assistência técnica & $-63,9630^{* * *}$ & $-104,3269$ & $-29,6812$ \\
$z_{4}$ - Escolaridade & $-75,4755^{* * *}$ & $-119,7423$ & $-44,8918$ \\
$z_{5}$ - Terras próprias & $-5,8644^{*}$ & -13.7198 & 0,8378 \\
$z_{6}$ - Sexo & $24,7564^{* *}$ & 6,030 & 47,3453 \\
$z_{7}$ - Crédito & 7,2765 & $-12,8158$ & 31,9721 \\
$\widehat{\boldsymbol{o}}_{\boldsymbol{e}}$ & $5,3502^{* * *}$ & 4,4172 & 7,3149
\end{tabular}

Fonte: elaborada pelos autores. Nota: *** significante a $1 \%$; ${ }^{* *}$ significante a $5 \%$; * significante a $10 \%$.

Novamente, a assistência técnica e o fato de o produtor possuir ensino médio como escolaridade mínima foram variáveis que condicionaram positivamente a eficiência econômico-ecológica dos municípios do bioma Amazônia. Desta forma, esses foram os dois fatores mais consistentes da análise, pois foram significativos em ambos os modelos e apresentaram o mesmo efeito sobre os escores estimados, reafirmando a importância de políticas educacionais na promoção de um ambiente mais sustentável nas práticas agropecuárias.

Já a variável que contempla o percentual da mão de obra com menos de 14 anos nos estabelecimentos registrou significância estatística na orientação aos produtos e esteve associada positivamente com o nível de ecoeficiência agropecuária de uma municipalidade representativa dessa região. Em outras palavras, quanto maior a proporção de pessoal ocupado abaixo de 14 anos, maior o desempenho das unidades produtivas, fato que está em desacordo com os resultados apresentados na literatura, que se baseiam em evidências de que essa mão de obra é menos produtiva que a composta por adultos (Ayenew et al., 2017). Além disso, essa questão esbarra em um outro problema, dessa vez de cunho social 
É importante sublinhar que um trabalho recente sobre ecoeficiência da produção agropecuária dos municípios amazônicos, elaborado por Rosano Peña et al. (2018), por meio de um arcabouço de fronteiras estocásticas, também obteve associação positiva dessa variável com o nível de ecoeficiência, reforçando os resultados encontrados neste artigo.

Similarmente, a variável terras próprias, que consiste na porcentagem de produtores que são proprietários dos estabelecimentos, foi significante estatisticamente nessa orientação, o que indica que um aumento nessa proporção está associado a um incremento na ecoeficiência da agropecuária amazônica em termos de maximização das receitas e da área preservada com APPs e reserva legal. Nesse sentido, Sabiha et al. (2017) estimaram a ecoeficiência por meio da DEA, e a propriedade de terras esteve significantemente relacionada com incrementos nos indicadores de ecoeficiência de produtores agrícolas de Bangladesh, o que reforça a importância de o produtor ser o dono do estabelecimento para a utilização de técnicas mais sustentáveis de produção. Em termos práticos, existe a possibilidade de o produtor proprietário receber um "prêmio" por manter suas áreas preservadas, nomeadamente a Compensação da Reserva Legal e a iniciativa Conserv, que visam reduzir o desmatamento legal.

Ainda, a variável sexo do produtor principal apresentou significância estatística nesse modelo e com sinal negativo para o coeficiente, fato que indica que mulheres que são produtoras agropecuárias tendem a ser menos ecoeficientes que homens. Essa evidência ainda é controvertida na literatura, haja vista que existem evidências empíricas que tanto demonstram uma associação positiva como negativa entre eficiência agrícola e sexo do produtor. Com efeito, Seymour (2017), ao estimar o desempenho de produtores rurais do Bangladesh, observou que menores níveis de desigualdade de gênero nos estabelecimentos entre homens e mulheres estão correlacionados com maior eficiência técnica da agricultura dessa região. Por outro lado, Kansiime et al. (2018), estimando a eficiência do uso de insumos na produção agrícola em Uganda, avaliaram que o produtor ser do sexo masculino esteve associado com incrementos no desempenho produtivo dessa localidade.

Tal resultado, assim como para os dados da ecoeficiência da agropecuária amazônica, pode estar relacionado com o fato de que produtores homens, geralmente, têm renda maior que as mulheres e também mais acesso a programas de assistência e extensão rural (Kansiime et al., 2018). Desta forma, essa é uma evidência da importância de direcionamento de políticas governamentais que focalizam especificamente esse público em termos de orientação técnica e diminuição de gaps de renda que possam existir.

Finalmente, a proporção de mão de obra familiar nos estabelecimentos e o acesso ao crédito não foram significantes estatisticamente, apesar das evidências da literatura de uma associação positiva. Ademais, ressalta-se que essa análise demonstrou a importância da escolha do modelo DEA para a estimação dos regressores do segundo estágio, em que o sinal e a significância estatística podem se alterar, a depender da escolha do pesquisador.

\subsection{Análise espacial da ecoeficiência}

Para uma análise regionalizada da ecoeficiência da agropecuária amazônica, inicia-se com a apresentação da distribuição espacial dos índices estimados, de forma a permitir uma primeira análise geográfica da distribuição clássica comumente apresentada. A Figura 1 demonstra os quartis dos escores municipais corrigidos e espalhados pelo território do bioma Amazônia. 


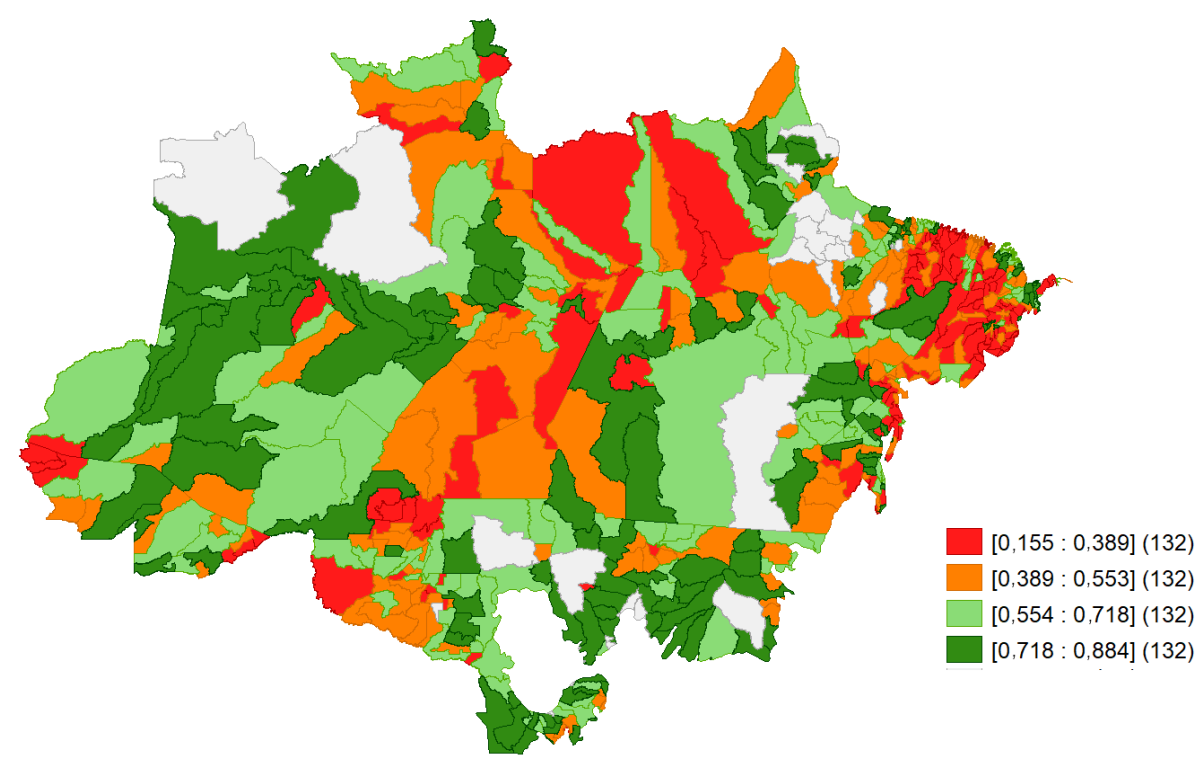

Figura 1. Distribuição espacial dos escores de ecoeficiência. Fonte: elaborada pelos autores.

Com isso, o ponto primário a ser destacado refere-se ao último quartil de ecoeficiência, pois, por conta do procedimento de bootstrap, não há municipalidades com desempenho máximo (índice igual a 1). Posteriormente, percebe-se a existência de distintos padrões produtivos e sustentáveis, pois a concentração por região geográfica é explícita no mapa. Desta forma, há uma concentração de municípios de alta ecoeficiência (verde-escuro), especialmente, nos estados do Amapá, Mato Grosso e Amazonas, cujos índices médios de eficiência econômica e ambiental foram de 0,69, 0,66 e 0,61, respectivamente. Além disso, essas regiões também concentraram grande parte dos municípios de ecoeficiência moderada (verde-claro), em que ainda os índices se mantiveram acima da média da amostra.

Entretanto, a sustentabilidade da agropecuária na Amazônia esteve em menores níveis e mais comprometida nos estados do Maranhão, Tocantins e Rondônia, em que os índices médios de ecoeficiência foram de 0,46, 0,50 e 0,51, respectivamente. De forma específica, na região nordeste do mapa, destaca-se a significativa concentração de municipalidades de baixa ecoeficiência (laranja) e muito baixa ecoeficiência (vermelho), o que indica que Maranhão e Tocantins são casos especiais de uma produção agrícola e pecuária com baixa preservação de áreas de APPs e reserva legal, bem como alto índice de impacto na biodiversidade por conta de baixa diversificação de culturas agrícolas. Para a primeira unidade federativa, o indicador médio de Shannon como exemplo foi de 0,61 , ao passo que, para a última, essa estatística foi de 0,81 , estando ambos acima da média amostral de 0,59.

Esses agrupamentos podem indicar a existência de clusters espaciais de ecoeficiência, bem como a existência de valores atípicos, representados por dados contrastantes de um município em relação à sua vizinhança, o que sugere a presença de outliers espaciais. Contudo, para analisar adequadamente essa distribuição, é necessário testar a dependência espacial desses escores por meio da estatística de Moran, que é uma medida de autocorrelação espacial de variáveis que pode apresentar esse comportamento regionalizado.

Sendo assim, para verificar essa hipótese, estimou-se o índice global de Moran, com base em uma matriz de pesos Queen normalizada de ordem 2. O procedimento de seleção dessa matriz considerou dois aspectos. O primeiro foi que os municípios são considerados vizinhos se estão em diagonal ou laterais em relação ao município de referência, o que aumenta o raio 
de vizinhança e está em consonância com trabalhos nacionais de ecoeficiência da agricultura (Rosano-Peña et al., 2020). O segundo foi considerar como vizinhança de um município o seu vizinho imediato e o vizinho mais próximo deste.

Ademais, essa combinação foi validada como a que gerou melhores resultados em termos de significado estatístico para o índice estimado de Moran. De fato, esse indicador foi positivo, com valor de $I=0,245$, e estatisticamente significativo para um nível de confiança de $99,9 \%$ via distribuição normal simulada ( $p$-valor $<0,01$ ), o que demonstra a presença de autocorrelação positiva da ecoeficiência agropecuária na Amazônia (Figura 2). De outra forma, isso implica que, para a amostra como um todo, os municípios e sua vizinhança apresentam valores de ecoeficiência próximos entre si e dependentes espacialmente (Rosano-Peña et al., 2020).

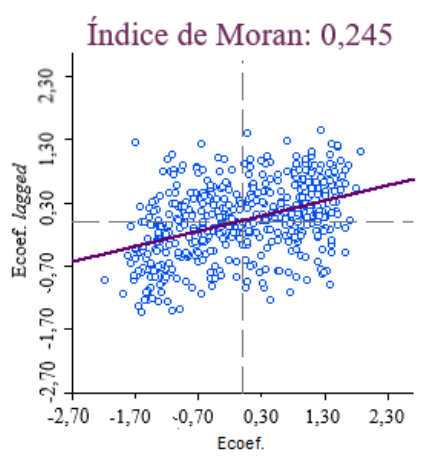

Figura 2. Diagrama de dispersão de Moran. Fonte: elaborada pelos autores.

Por esse resultado, já é possível afirmar que o espaço está correlacionado com a eficiência econômico-ecológica da agricultura na Amazônia, mas, para analisar padrões espaciais locais, empregou-se também o índice local de Moran, cujos resultados estão registrados na Figura 3, na qual se apresentam os indicadores locais dos municípios com valor significante estatisticamente a um nível de confiança de $99,5 \%$. Na categoria Alto-Alto, estão contidos os municípios em que a sua ecoeficiência e a de sua vizinhança foram altas, indicando associação positiva em agrupamentos regionais. Ainda, na categoria Baixo-Baixo, estão os municípios em que a sua ecoeficiência e a de sua vizinhança foram baixas, denotando uma associação negativa de agrupamentos de ecoineficiência elevada.

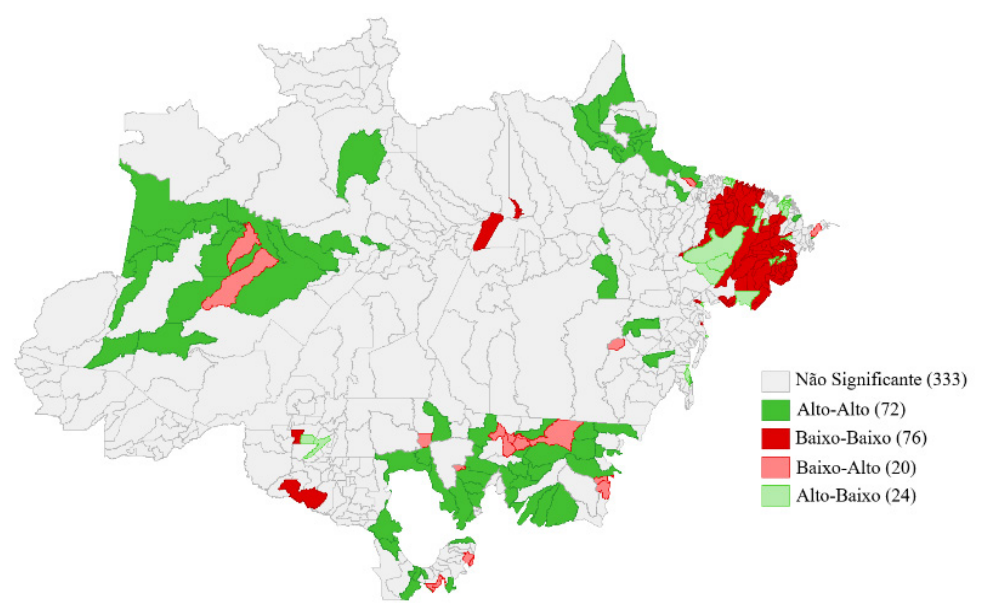

Figura 3. Distribuição da dependência espacial de ecoeficiência. Fonte: elaborada pelos autores. 
Por outro lado, as categorias Alto-Baixo e Baixo-Alto contêm os casos em que a ecoeficiência de uma municipalidade é atípica em relação à sua vizinhança, quando um município apresenta um desempenho alto e está inserido em uma vizinhança de desempenho baixo e quando ele apresenta um desempenho baixo e está rodeado por casos de desempenho alto. Desta forma, os estratos mais escuros no mapa representam clusters de ecoeficiência agropecuária, ao passo que os estratos mais claros representam municipalidades que são outliers espaciais em relação aos seus vizinhos.

Pelo mapa, é possível observar que o estrato com maior frequência foi o grupo Baixo-Baixo (39\% dos casos), o que aponta para uma existência significativa de clusters de baixa ecoeficiência, ou seja, de municípios cujo baixo nível ambiental, econômico, de sustentabilidade e da agropecuária é similar ao de seus vizinhos e dependente deles. Reforçando a análise anterior da distribuição espacial da ecoeficiência, observa-se que, em sua maioria, esses agrupamentos estavam localizados nos estados de Tocantins e Maranhão.

Ainda, com uma frequência pouco distinta, o grupo Alto-Alto correspondeu a $37 \%$ dos casos significantes estatisticamente, fato que denota a presença relevante de clusters de alta ecoeficiência, compreendidos por municipalidades cuja boas práticas de sustentabilidade agropecuária estão autocorrelacionadas espacialmente. Novamente, analisando a localização de maior concentração desses casos, Mato Grosso, Amazonas e Amapá continham a maioria dos municípios desse padrão espacial, de forma que a agricultura mecanizada e de maior diversificação de culturas dessas regiões foi um fator explicativo para a formação desses grupos.

Por último, os municípios das categorias Alto-Baixo e Baixo-Alto representaram, conjuntamente, $22 \%$ do total, sendo também um ponto relevante de análise, pois são regiões de desempenho atípico em relação à sua vizinhança geográfica. Esses casos estão espalhados a nordeste (Alto-Baixo), centro (Baixo-Alto) e noroeste (Baixo-Alto) do mapa. Portanto, corroborando com Rosano-Peña et al. (2020), um dos poucos artigos a abordar a dependência espacial da ecoeficiência da agricultura brasileira, é factível definir quatro prioridades de intervenção ambiental em âmbito regional:

1. Maior prioridade: municípios do estrato Baixo-Baixo, com baixos índices de ecoeficiência, haja vista que esses são casos de efeito de transbordamento (spillover) negativo.

2. Prioridade intermediária: municípios do estrato Alto-Baixo, onde existe a possibilidade de "ilhas de excelência", com bom desempenho econômico e ambiental, expandirem suas experiências para a vizinhança.

3. Segunda prioridade intermediária: municípios agregados em Baixo-Alto, em que a difusão de melhores práticas do entorno deve ser absorvida por esses exemplos atípicos de baixa sustentabilidade agropecuária.

4. Menor prioridade: municípios agregados em Alto-Alto, composto por regiões de clusters de alta ecoeficiência e que devem ser replicados para outras localidades.

Desta forma, essa análise fornece importantes evidências da dependência espacial da ecoeficiência agropecuária nos municípios da Amazônia. Espera-se, assim, contribuir para os estudos atuais e para a elaboração de políticas públicas para a agricultura e pecuária da região, pois ainda são poucos os trabalhos que consideram essa hipótese no estudo da sustentabilidade para esse tipo de atividade econômica. Além disso, é uma discussão que pode fornecer insights para futuros estudos que, para além da análise de autocorrelação espacial, estimem o efeito do espaço geográfico na mensuração da ecoeficiência e considerem nos modelos econométricos, 
com os devidos testes para identificar a necessidade de regressões espaciais, a possibilidade de que o espaço seja um fator condicionante desse fenômeno.

Outra sugestão, mediante a averiguação dos resultados, é traçar um panorama de ecoeficiência, especialmente, para a região MATOPIBA, dada a rápida expansão da agropecuária naquela região, bem como indicativos de baixa ecoeficiência.

\section{Conclusões}

A produção agropecuária dos municípios localizados no bioma Amazônia tem importante desempenho econômico para a produção de agroalimentos em âmbito nacional. Entretanto, a produção na região tem sido foco de discussões que envolvem ambientalistas, produtores e comunidade externa: de um lado, posições conservacionistas que se preocupam com a exploração no bioma amazônico, mas desconsideram os aspectos sociais e culturais da produção na região; por outro lado, agricultores e pecuaristas exploram o bioma de forma irresponsável e não se atentam aos possíveis ganhos de eficiência associados à conservação da Amazônia e seus ecossistemas. Ao considerar essas duas visões, este estudo abordou o processo de expansão da fronteira agrícola e a incorporação de novas tecnologias no processo produtivo, com enfoque nos aspectos ambientais.

O estudo forneceu discussões acerca da manutenção da agropecuária nos municípios situados na Amazônia concomitantemente à conservação do bioma. Em outras palavras, identificaramse as possibilidades de conciliação entre eficiência econômica e eficiência ecológica dessa atividade na região. Ademais, discutiram-se os determinantes socioeconômicos e produtivos que promovem aumentos na produtividade agropecuária ao mesmo tempo que mitigam os danos ambientais, principalmente os efeitos relacionados ao desmatamento e à deterioração da diversidade biológica da floresta amazônica. Também se identificou a existência da concentração espacial dos municípios ecoeficientes. Essa última contribuição permite aos formuladores de políticas o delineamento de medidas direcionadas para determinadas regiões.

Em termos metodológicos, a análise da ecoeficiência da produção agropecuária dos municípios da Amazônia por meio da DEA em dois estágios e do indicador espacial de Moran permitiu, primeiramente, a mensuração de índices de ecoeficiência corrigidos de viés com a regressão de variáveis explicativas e um segundo estágio. Já a segunda proposta metodológica permitiu testar a hipótese de dependência espacial desse fenômeno. Os métodos empregados forneceram consistência e robustez à avaliação dos determinantes do indicador de sustentabilidade e permitiram a identificação das regiões em que os fenômenos da produtividade ecoeficiente eram mais evidentes.

Os principais resultados apontaram, por meio da DEA-BTR primeiro estágio, que a ecoeficiência média corrigida de viés foi de 0,5490, uma diferença de 0,1256 para os escores determinísticos. Além disso, ao passo que, nesse modelo, 96 municipalidades foram consideradas ecoeficientes, no modelo com bootstrap a ecoeficiência máxima foi de 0,8837 . Isso indica que o modelo clássico DEA com retornos variáveis de escala superestimou o desempenho econômico-ecológico da agricultura na Amazônia. Esse resultado confirma que a metodologia empregada foi a mais adequada, por isso recomenda-se seu uso para futuros estudos com objetivos similares aos propostos na presente investigação.

Além disso, no segundo estágio, estimaram-se os fatores determinantes da ecoeficiência agropecuária nessas municipalidades. As variáveis exógenas mais consistentes, com significância estatística e sinal igual para os dois modelos, foram assistência técnica e nível de escolaridade do produtor. Com efeito, a promoção de programas de orientação técnica no meio rural e o 
produtor possuir pelo menos ensino médio condicionaram positivamente a sustentabilidade agropecuária dos municípios da Amazônia. Desta forma, ressalta-se a importância de se fortalecer políticas públicas de extensão rural e de garantia e provisão de educação mínima para os produtores agrícolas desse bioma.

Por fim, a análise espacial, ainda que de caráter exploratório, evidenciou a existência de autocorrelação espacial positiva dos índices estimados de ecoeficiência. Isso significa que um município nesse bioma tendia a ter níveis de eficiência econômica e ambiental similares ao de seus vizinhos. Esse resultado corrobora políticas em âmbito regional dentro do bioma. Ademais, a mensuração local do índice de Moran permitiu visualizar a existência de padrões espaciais locais, em que se destacou a existência de clusters de baixa ecoeficiência nos estados do Maranhão e Tocantins e de alta ecoeficiência no Mato Grosso e Amazonas.

Uma limitação desta pesquisa foi o condicionamento da análise em dados transversais, em um modelo estático, além da análise espacial ser restrita à discussão da autocorrelação dos índices de ecoeficiência. Com isso, recomenda-se que estudos futuros considerem a hipótese de o espaço ser um fator condicionante da ecoeficiência e avaliem a dinâmica da ecoeficiência agropecuária no bioma amazônico, a fim de estimar ganhos ou perdas de produtividade e sustentabilidade.

\section{Referências}

Anselin, L. (1995). Local Indicators of Spatial Association-LISA. Geographical Analysis, 27(2), 93-115. http://dx.doi.org/10.1111/j.1538-4632.1995.tb00338.x

Ayenew, H. Y., Estruch, E., Sauer, J., Abate-Kassa, G., Schickramm, L., \& Wobst, P. (2017). Decent rural employment and farm production efficiency: empirical evidence from Tanzania and Ethiopia. Agricultural Economics, 48(5), 587-596. http://dx.doi.org/10.1111/agec.12359

Banker, R. D., Charnes, A., \& Cooper, W. W. (1984). Some Models for Estimating Technical and Scale Inefficiencies in Data Envelopment Analysis. Management Science, 30(9), 1078-1092. http://dx.doi.org/10.1287/mnsc.30.9.1078

Beltrán-Esteve, M., Gómez-Limón, J. A., \& Picazo-Tadeo, A. J. (2012). Assessing the impact of agri-environmental schemes on the eco-efficiency of rain-fed agriculture. Spanish Journal of Agricultural Research, 10(4), 911-925. http://dx.doi.org/10.5424/sjar/2012104-3088

Berre, D., Corbeels, M., Rusinamhodzi, L., Mutenje, M., Thierfelder, C., \& Lopez-Ridaura, S. (2017). Thinking beyond agronomic yield gap: Smallholder farm efficiency under contrasted livelihood strategies in Malawi. Field Crops Research, 214, 113-122. http://dx.doi.org/10.1016/j.fcr.2017.08.026

Bogetoft, P., \& Otto, L. (2011). Benchmarking with DEA, SFA, and R. New York : Springer.

Bonfiglio, A., Arzeni, A., \& Bodini, A. (2017). Assessing eco-efficiency of arable farms in rural areas. Agricultural Systems, 151, 114-125. http://dx.doi.org/10.1016/j.agsy.2016.11.008

Brianez, G. P., \& Sabbag, O. J. (2021). Análise envoltória de dados na eficiência inovativa de propriedades leiteiras. Exacta. No prelo. https://doi.org/https://doi.org/10.5585/ exactaep.2021.18429.

Brundtland, G. H. (1987). The Brundtland report: 'our common future'. Medicine and War, 4(1), 17-25.

Chandio, A. A., Jiang, Y., Gessesse, A. T., \& Dunya, R. (2019). The nexus of agricultural credit, farm size and technical efficiency in sindh, pakistan: a stochastic production frontier approach. Journal of the Saudi Society of Agricultural Sciences, 18(3), 348-354. http://dx.doi. org/10.1016/j.jssas.2017.11.001 
Charnes, A., Cooper, W. W., \& Rhodes, E. (1978). Measuring the efficiency of decision making units. European Journal of Operational Research, 2(6), 429-444. http://dx.doi.org/10.1016/03772217(78)90138-8

Clemente, F., Gomes, M. F. M., \& Lírio, V. S. (2015). Análise da eficiência técnica de propriedades citrícolas do estado de São Paulo. Economia Aplicada, 19(1), 63-79. http://dx.doi. org/10.1590/1413-8050/ea104786

Farrell, M. J. (1957). The measurement of productive efficiency. Journal of the Royal Statistical Society. Series A (General), 120(3), 253-290. http://dx.doi.org/10.2307/2343100.

Godoy-Durán, Á., Galdeano- Gómez, E., Pérez-Mesa, J. C., \& Piedra-Muñoz, L. (2017). Assessing ecoefficiency and the determinants of horticultural family-farming in southeast Spain. Journal of Environmental Management, 204, 594-604. http://dx.doi.org/10.1016/j.jenvman.2017.09.037

Guesmi, B., Serra, T., Radwan, A., \& Gil, J. M. (2018). Efficiency of Egyptian organic agriculture: a local maximum likelihood approach. Agribusiness, 34(2), 441-455. http://dx.doi.org/10.1002/agr.21520

Huy, H. T., \& Nguyen, T. T. (2019). Cropland rental market and farm technical efficiency in rural Vietnam. Land Use Policy, 81, 408-423. http://dx.doi.org/10.1016/j.landusepol.2018.11.007

Instituto Brasileiro de Geografia e Estatística - IBGE. (2017). Censo agropecuário 2017: resultados definitivos. Recuperado em 1 de março de 2021, de https://sidra.ibge.gov.br/pesquisa/ censo-agropecuario/censo-agropecuario-2017

Instituto Nacional de Pesquisas Espaciais - INPE. (2020). Portal TerraBrasilis: incrementos de desmatamento na Amazônia. Recuperado em 1 de março de 2021, de http://terrabrasilis. dpi.inpe.br/app/dashboard/deforestation/biomes/amazon/increments

Kansiime, M. K., van Asten, P., \& Sneyers, K. (2018). Farm diversity and resource use efficiency: targeting agricultural policy interventions in East Africa farming systems. NJAS Wageningen Journal of Life Sciences, 85(1), 32-41. http://dx.doi.org/10.1016/j.njas.2017.12.001

Khan, A. S., \& Silva, L. M. R. (1997). Assistência técnica, eficiência na utilização dos fatores de produção e da produtividade diferencial em propriedades rurais. Revista de Economia e Sociologia Rural, 35(2), 95-114. Recuperado em 1 de março de 2021, de http://www. revistasober.org/article/5da37ad10e8825996eba68e1

Kuosmanen, T., \& Kortelainen, M. (2005). Measuring eco-efficiency of production with data. Journal of Industrial Ecology, 9(4), 59-72. http://dx.doi.org/10.1162/108819805775247846

Masuku, M. B., Raufu, M. O., \& Malinga, N. G. (2014). The impact of credit on technical efficiency among vegetable farmers in Swaziland. Sustainable Agriculture Research, 4(1), 114. http:// dx.doi.org/10.5539/sar.v4n1p114

Medina, G. da S. (2019). Participação do capital brasileiro na cadeia produtiva do leite : estratégia para investimentos em segmentos do agronegócio nacional. Revistas de Estudos Sociais, 22(44), 146-167.

Moran, P. A. P. (1948). The interpretation of statistical maps. Society, 10(2), 243-251.

Perman, R., Ma, Y., McGilvray, J., \& Common, M. (2003). Natural resource and environmental economics. Harlow: Pearson.

Rosano Peña, C., Serrano, A. L. M., de Britto, P. A. P., Franco, V. R., Guarnieri, P., \& Thomé, K. M. (2018). Environmental preservation costs and eco-efficiency in Amazonian agriculture: Application of hyperbolic distance functions. Journal of Cleaner Production, 197, 699-707. http://dx.doi.org/10.1016/j.jclepro.2018.06.227 
Rosano-Peña, C., Almeida, C. A. R., Rodrigues, E. C. C., \& Serrano, A. M. L. (2020). Dependência espacial da ecoeficiência da agricultura em São Paulo. Brazilian Business Review, 17(2), 328-343. http://dx.doi.org/10.15728/bbr.2020.17.3.5

Sabiha, N. E., Salim, R., \& Rahman, S. (2017). Eco-efficiency of high-yielding variety rice cultivation after accounting for on-farm environmental damage as an undesirable output: an empirical analysis from Bangladesh. The Australian Journal of Agricultural and Resource Economics, 61(2), 247-264. http://dx.doi.org/10.1111/1467-8489.12197

Seymour, G. (2017). Women's empowerment in agriculture: Implications for technical efficiency in rural Bangladesh. Agricultural Economics (United Kingdom), 48(4), 513-522. http://dx.doi. org/10.1111/agec.12352

Silva, J. S., Ferreira, M. de O., \& Lima, J. R. F. (2017). Eficiência técnica dos produtores de manga do Vale do São Francisco. Revista de Economia e Agronegócio, 15(1), http://dx.doi. org/10.25070/rea.v15i1.367

Silva, J.V. B., \& Thomé, K. M. (2021). (Eco)eficiência da produção alimentar: uma revisão sistemática da literatura. Revista em Agronegócio e Meio Ambiente, 14(3), e8055.

Simar, L., \& Wilson, P. W. (2007). Estimation and inference in two-stage, semi-parametric models of production processes. Journal of Econometrics, 136(1), 31-64. http://dx.doi.org/10.1016/j. jeconom.2005.07.009

Toma, P., Miglietta, P. P., Zurlini, G., Valente, D., \& Petrosillo, I. (2017). A non-parametric bootstrapdata envelopment analysis approach for environmental policy planning and management of agricultural efficiency in EU countries. Ecological Indicators, 83, 132-143. http://dx.doi. org/10.1016/j.ecolind.2017.07.049

Zulfiqar, F., Datta, A., \& Thapa, G. B. (2017). Determinants and resource use efficiency of "better cotton": an innovative cleaner production alternative. Journal of Cleaner Production, 166, 1372-1380. http://dx.doi.org/10.1016/j.jclepro.2017.08.155 